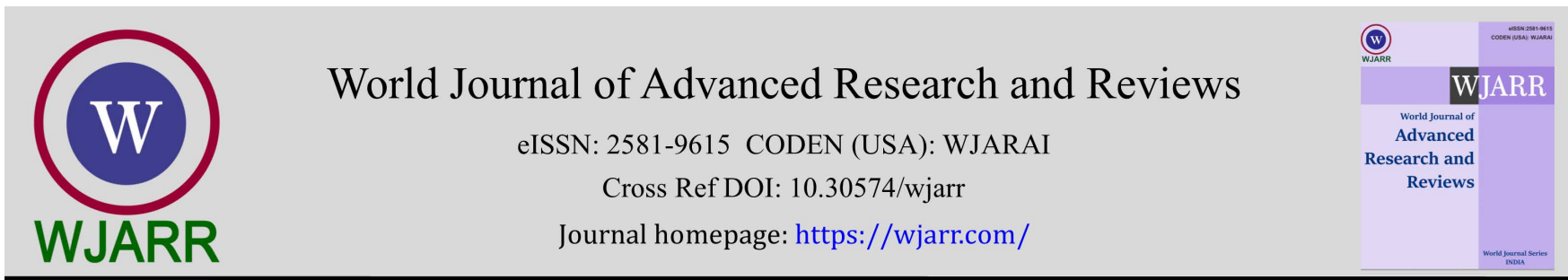

(RESEARCH ARTiClE)

Check for updates

\title{
Assessment of environmental condition and drying process of the plants on the concentration of alkaloids and cytotoxicity of traditional Ayahuasca Tea
}

\author{
Miranda Ordilena Ferreira de 1,2,* Almeida Marcílio de 2, Sousa Ilza Maria de Oliveira 3, Ruiz Ana Lúcia \\ Tasca Gois ${ }^{3}$, Costa José Luiz da ${ }^{3}$, Medeiros Raquel da Silva ${ }^{1}$ and Foglio Mary Ann ${ }^{3}$ \\ ${ }^{1}$ Department of Biodiversity, National Institute of Amazonian Research, Manaus, Amazonas, Brazil. \\ 2 Department of Biological Sciences, Higher School of Agriculture "Luiz de Queiroz", University of São Paulo, Piracicaba, \\ São Paulo, Brazil. \\ ${ }^{3}$ Faculty of Pharmaceutical Sciences, University of Campinas, São Paulo, Brazil.
}

World Journal of Advanced Research and Reviews, 2021, 10(02), 075-089

Publication history: Received on 03 April 2021; revised on 06 May 2021; accepted on 09 May 2021

Article DOI: https://doi.org/10.30574/wjarr.2021.10.2.0209

\begin{abstract}
Introduction: Ayahuasca is a traditional psychoactive tea of Amazonian indigenous, used medicinal and spiritual purposes. Wide variation in the concentration of $N, N$-dimethyltryptamine (DMT), Harmaline (HRL), Harmine (HRM) and Tetrahydroharmine (THH) alkaloids in Ayahuasca has been reported worldwide.
\end{abstract}

Objective: To evaluate the causes of variations in alkaloids concentrations of Ayahuasca prepared with fresh and dehydrated plants from different environments and determine the best drying method to plants according to alkaloids content and cytotoxicity of Ayahuasca tea.

Material and methods: The environment interference on the alkaloids of the two species was evaluated in samples of Ayahuasca tea prepared with fresh plants. The most suitable drying process to the two species was evaluated in sample Ayahuasca tea prepared with plants submitted to drying under the sun conditions and five different temperatures in forced circulation oven. The concentration of the alkaloids determined by high performance liquid chromatography with UV-vis detector with diode array detection (HPLC-DAD). The in vitro cytotoxicity of Ayahuasca was evaluated in human keratinocytes cells (HaCaT) by colorimetric assay.

Results: Environmental characteristics, preparation process and temperature of plants drying interfered on DMT, HRL, HRM and THH concentrations of Ayahuasca. No effect cytotoxicity was detected with relationship to psychoactive alkaloids in samples of Ayahuasca tea prepared with fresh or dried plants.

Conclusion: Concentration of DMT, HRL, HRM and THH alkaloids in Ayahuasca are influenced by plants environmental. The most suitable drying process was obtained in forced circulation oven at 43 and $45^{\circ} \mathrm{C}$ to $P$. viridis leaves and $B$. caapi stems respectively. The Ayahuasca prepared with fresh or dry plants no showed cytotoxicity in human keratinocytes cells.

Keywords: Traditional Ayahuasca; Alkaloids; Dry Plants; Psychotria; Banisteriopsis; Cytotoxicity.

\footnotetext{
*Corresponding author: Ordilena Ferreira de Miranda, Phone: (+55) 92 992792736, Email:ordilena@inpa.gov.br Department of Biodiversity, National Institute of Amazonian Research, Manaus, Amazonas, Brazil. 


\section{Graphical abstract}

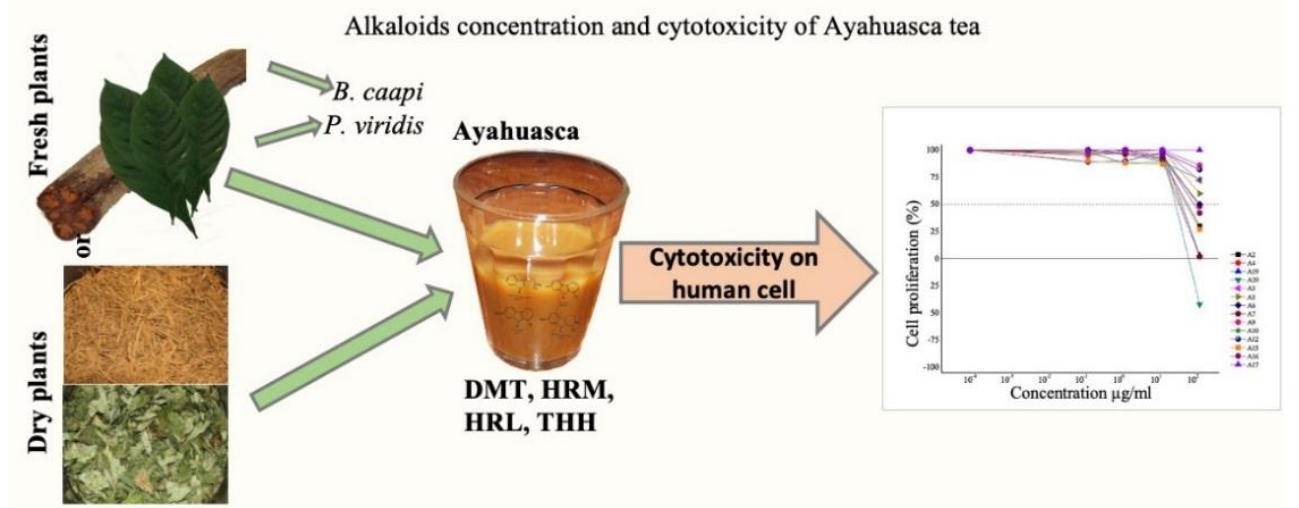

\section{Introduction}

Ayahuasca tea is a decoction prepared with leaves of $P$. viridis shrub popularly known as "rainha", "chacrona" or "chacruna" and stems of B. caapi commonly known as "mariri", "Ayahuasca", "caapi", "jagube" [1-3]. The decoction of the plants together is the way of preparing traditional Ayahuasca. This tea has been used in traditional indigenous medicine of the Amazonian peoples for healing and also in spiritual rituals since pre-Columbian times [4-6]. In several countries, such as Colombia, Peru and Brazil it is the fundamental element of indigenous cultures [7, 8]. The preparation is highlighted for the psychoactive potential triggered by the synergism of the compounds $N, N$-dimethyltryptamine alkaloids (DMT) present in Psychotria viridis leaves together with the $\beta$-carbolinic group compounds: harmine (HRM), harmaline (HRL), and tetrahydroharmine (THH) (Figure. 1) found in the stems of Banisteriopsis caapi [9], and are considered by tea consumers as a result of consciousness expansion.

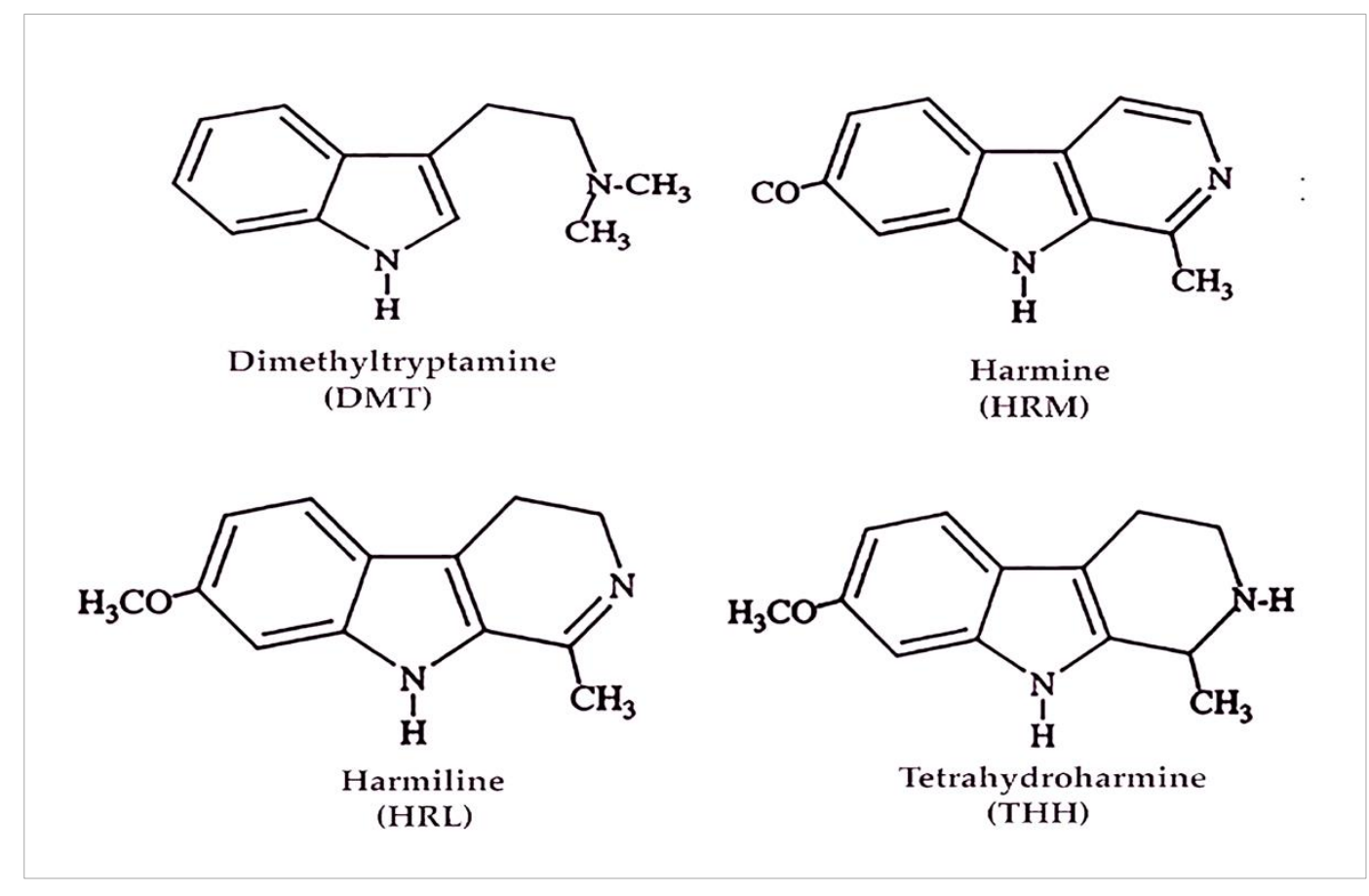

Figure 1 Chemical structures of the psychoactive alkaloids of Ayahuasca tea. $N, N$-dimethyltryptamine (DMT), and $\beta$ carbolines harmine (HRM), harmaline (HRL) and tetrahydroharmine (THH).

The incorporation of this beverage for healing purposes and religious support in urban contemporary society emerged from indigenous and caboclas populations of tropical forests [10]. Studies of the bioactive compounds of Ayahuasca tea $[1,11-13]$ and of the plants that are used for the preparation $[14,15]$ were prompted by increased religious and therapeutic use of Ayahuasca in the United States and several other countries in Europe, but also by the worldwide trend for psychedelic therapy research. The entheogenic effect of Ayahuasca was attributed to a direct 
relationship with DMT content, that when taken orally is inactivated by visceral monoamine oxidase (MAO). This effect is reversed by the action of $\beta$-carbolines, which are highly active reversible MAO inhibitors, protecting DMT from deamination by MAO, enabling the beverage's oral use [5].

Concentration variations of DMT, HRM, HRL and THH alkaloids were found in Ayahuasca samples consumed in European countries, and in some cases, synthetic product were also detected [16]. Ayahuasca tea consumed in these countries, is known to be generally produced in Amazonian countries and shipped abroad. Silveira [17] quantified the alkaloids in Ayahuasca samples stored throughout seven days at high temperature, mimicking the mail transportation conditions, not finding any significant decrease of DMT, whereas meaningful variations of $\beta$-carbolines alkaloids were detected, with detection of THH decrease of up to $67.9 \%$. Other studies have also detected concentrations variations of these alkaloids in Ayahuasca samples of the same source [11]. In samples prepared by traditional ritualistic procedures, which consists in the decoction of $P$. viridis leaves together with the stems of $B$. caapi, alkaloid variation reached a tenfold magnitude [13]. For other hand, great variability of $B$. caapi, with at least 30 different varieties described and cataloged, which have a direct relationship with different levels of alkaloids found in Ayahuasca preparations, aside from various plant proportion used by the different groups $[5,18]$ was also reported.

Regarding origin, plant-environment relationship interferes with the secondary metabolism process, acting as a driving force for the biosynthesis of phytochemicals in plants [19, 20]. This approach was reported by Miranda et al. [15] for $P$. viridis, the species that contributes with DMT, but in this study the authors did not report the alkaloid content in the tea. Another factor that influences secondary plant metabolism is the genetic diversity within the species, well described for the species used in the Ayahuasca beverage and for other medicinal species $[18,21]$. To ensure a safe use of Ayahuasca in countries outside the geographical area of naturally occurring plants (Europe and North America), a strategy would be to provide inputs for the preparation of Ayahuasca in loco at these destinations. To achieve a quality product that provides the expected effect an alternative is the plant dehydration inside parameters that maintain phytochemical quality ensured. The drying process generates a stable product that could be easily shipped, with a reduced volume compared to the fresh plant, furthermore, the plant would be available during the whole year long [22]. Despite being considered one of the most usual and fundamental processes for preserving medicinal plants, drying can exacerbate loss of bioactive compounds depending on the temperature applied [23].

The interference of both the environment and drying condition in the concentrations of bioactive compounds from medicinal plants is well documented [24, 25]. Despite the increased consumption of Ayahuasca in various extraAmazonian countries, as well as their described pharmacological and therapeutic potential, yet data establishing the contribution of the environmental effect on the variation of alkaloid content in B. caapi and P. viridis are still to be determined. Nevertheless, there no studies that access these plants drying temperature parameters.

The literature data together with the breakthrough use of this tea points out the need to establish quality control parameters for the use of Ayahuasca beverages. The first point refers to the alkaloids variations in the tea found worldwide, with another issue referring to strategies to ensure that no adulteration has been introduced to Ayahuasca beverages consumed in other countries outside the Amazon regions. Ensuring the effect of Ayahuasca traditionally used by amazon peoples.

To address the causes of variation in alkaloids content in Ayahuasca tea, and determine the most suitable drying process to plants used in the preparation this tea, herein we evaluated of the concentration of DMT, HRM, HRL and THH (Figure.1) from plants collected in two different ecosystems in the Amazon region, and we test the influence of different temperatures and dry method on the content of these alkaloids in the final product. Furthermore, the cytotoxicity of Ayahuasca tea prepared with fresh and dried plants was tested in human keratinocyte cells.

\section{Material and methods}

\subsection{Collection areas and plant material}

Wild B. caapi, and cultivated P. viridis samples from two distinct ecosystems were collected in the Brazilian Amazon, located $360 \mathrm{~km}$ apart from each other. One of the locations was Campinarana (CAMP), stationed south of Roraima State $\left(00^{\circ} 57^{\prime} 03^{\prime \prime} \mathrm{N}\right.$ and $\left.59^{\circ} 54^{\prime} 39^{\prime \prime} \mathrm{O}\right)$ and the other was Terra Firme (TF), located in the North of the State of Amazonas $\left(02^{\circ} 02^{\prime} 04^{\prime \prime} \mathrm{S} ; 60^{\circ} 01^{\prime} \mathrm{O}\right)$. Both sites share the same broad climate type, considered as humid equatorial $A f$, according to Koppen [26], without clear stabilization seasons and marked by annual rain seasonally [27]. Each ecosystem in this study was characterized according to data previously described in the literature $[15,28,29]$ and by field observations. 
For all analyzes, the plant material was collected from individuals randomly chosen within each area, five individuals of wild B. caapi and 20 P. viridis trees cultivated in an agroforest, between 6 and 10 am in January/2016, August/2016, November/2017 and February/2019 were collected.

Species names were verified in http://www.theplantlist.org and the material identified under Voucher INPA No. 282931, 282932, 282933, 282934, 282935, deposited in the Herbarium of National Institute of Amazonian Research.

\subsection{Pre-processing of plants and preparation of Ayahuasca}

After each collection, the leaves and stems samples were washed in running water. Thereafter, B. caapi stems were preprocessed by smashing the shoots with wooden sticks for the separation of fibers. During pre-processing of the plant material collected in Janeiro/2016, August/2016 and collection half in November/2017, the leaves and stems were weighed separately, and then divided the samples of each species into two batches of equal weights. The first batch was used to prepare Ayahuasca with fresh plants, whereas the second batch was subjected to drying at temperatures of 60 ${ }^{\circ} \mathrm{C}, 50^{\circ} \mathrm{C}$ and $40^{\circ} \mathrm{C}$ before tea preparation, and resulting tea was analyzed to determine the DMT, HRM, HRL, and THH alkaloid content.

The other samples that were gathered in November/2017 (collection half) and February/2019 being pre-processed as previously described, however B. caapi stems and $P$. viridis leaves were subjected to different drying conditions according to the material of each species used in Ayahuasca preparation: a) stems at $45{ }^{\circ} \mathrm{C}$ and leaves $40{ }^{\circ} \mathrm{C}$; (b) stems and leaves in the sun and; (c) stems at $45^{\circ} \mathrm{C}$ and leaves at $43^{\circ} \mathrm{C}$. After drying, this material was used to prepare Ayahuasca beverage and determine alkaloid content.

For drying purposes, a forced circulation oven with air renewal and controlled temperature (TE 394/3 Tecnal) was used. A mesh trays was used for drying plant material in the sun. Drying was monitored by weighing samples using a precision weighing-scale at $12 \mathrm{~h}$ intervals and then reduced to $6 \mathrm{~h}$ when the material reached $50 \%$ of the initial weight, maintaining this interval until constant weight. After complete drying, the plant materials were packed in plastic bags, protected from light and stored in boxes until the time of use.

The maximum moisture content of the plants was measured according to Silveira [30] The $B$. caapi stems and $P$. viridis leaves samples were submerged in water for saturation until reaching constant weight, considering this the maximum fresh weight (FW). To determine dry weight (DW), the samples were dried in forced circulation oven with air renewal (TE $394 / 3 \mathrm{Tecnal}$ ) at $90^{\circ} \mathrm{C}$ for stems and $70^{\circ} \mathrm{C}$ for leaves. Weighing was carried out at a $24 \mathrm{~h}$ interval, being considered dry weight when the difference between two consecutive weightings was less than 1\%. Maximum moisture content (MC) was calculated as MC (\%) = (FW - DW)/FW x 100.

Ayahuasca, either with fresh or dehydrated plants, was prepared following the ritual adopted by the Centro Espírita Beneficente União do Vegetal (CBUDV) with define proportions of $P$. viridis leaves and B. caapi stems and water volume, whereas fire pressure and cooking time remained constant in all preparations for analysis. The average yield was 5-7 L of tea for each batch. Ayahuasca was then stored in a plastic container while still warm (about $60^{\circ} \mathrm{C}$ ), without air inside the bottle to minimize the process of fermentation. Thereafter the samples were left to cool at room temperature and subsequently stored at $5^{\circ} \mathrm{C}$.

\subsection{High Performance Liquid Chromatography Analysis with UV-vis Detector with Diodes Arrangement (HPLC-DAD)}

\section{Sample preparation}

The liquid samples of Ayahuasca were concentrated under vacuum (FISATON@) until attaining approximately $10 \%$ of the initial volume. They were then stored in appropriate containers and frozen at $-80^{\circ} \mathrm{C}$ and further freeze-dried at 4 atm pressure for 72 hours. The samples were stored, protected from light, at $5^{\circ} \mathrm{C}$. Aliquots $(10 \pm 1 \mathrm{mg})$ of each Ayahuasca sample were weighed, transferred into a volumetric flask (10mL) and dissolved in HPLC grade methanol under vigorous stirring (vortex) using ultrasound (10 min), adjusting the final volume to $10 \mathrm{~mL}(1$ $\mathrm{mg} / \mathrm{mL}$ stock solution). At the time of analysis, an aliquot $(200 \mu \mathrm{L})$ of each stock solution was mixed with HPLC grade methanol $(800 \mu \mathrm{L})$ in a $2 \mathrm{~mL}$ conical polypropylene tube under vortexing $(1,400 \mathrm{rpm}, 10 \mathrm{~min})$ and centrifuged $(12,000 \mathrm{rpm}, 5 \mathrm{~min})$. Thereafter an aliquot $(200 \mu \mathrm{l})$ from each supernatant was transferred to a glass auto sampler bottle containing $800 \mu \mathrm{L}$ of methanol and homogenized by vortex for further analysis. 


\subsection{Preparation of Standard Solutions}

The harmine (HRM) and harmaline (HRL) standards were purchased from Sigma-Aldrich (Steinheim, Germany), and Tetrahydroharmine (THH) from Cayman Chemical, whereas $N, N$-dimethyltryptamine (DMT) was synthesized by the tryptamine dimethylation method [11,31]. For each analyte a calibration curve containing five points was plotted, ranging from 100 to $1000 \mu \mathrm{g} / \mathrm{mL}$, obtained through linear regression (the area under the curve versus concentration), considering $\mathrm{R}^{2} \geq 0.98$.

\subsection{Analysis conditions by High Performance Liquid Chromatography Analysis with UV-vis with Diode Array Detection (HPLC-DAD)}

Lanaro [32] described the method used. The experiment was carried out using a HPLC Prominence System (Shimadzu, Kyoto, Japan). An Atlantis T3 column $(150 \times 3.0 \mathrm{~mm}, 3 \mu \mathrm{m})$ equipped with an Atlantis T3 protection column $(30 \times 10 \mathrm{~mm}$, $5 \mu \mathrm{m}$ ) (Waters Corporation, Milford, MA, USA) maintained at $35^{\circ} \mathrm{C}$. The mobile phase was a solution of phosphoric acid in ultrapure water $(10 \mathrm{mmol} / \mathrm{L}, \mathrm{pH}$ adjusted to 3.0 with triethylamine, A) and HPLC grade acetonitrile (B). Gradient elution, with a flow rate of $1 \mathrm{~mL} / \mathrm{min}$, started with $40 \%$ A and $60 \%$ B maintained for 1 min and then a gradual change to $5 \% \mathrm{~A}$ and $95 \% \mathrm{~B}$ over the next 13 min., with this final proportion being maintained for 5 min. The column was rebalanced to $60 \% \mathrm{~B}$ over $0.5 \mathrm{~min}$ and maintained at that concentrations for $3 \mathrm{~min}$ (total gradient time $=21 \mathrm{~min}$ ). The temperature of the auto sampler was not controlled, and the injection volume was $10 \mu \mathrm{L}$. The diode array detector at $35^{\circ} \mathrm{C}$ was adjusted to acquire spectra from 195 to $600 \mathrm{~nm}$. For quantification, the chromatograms were obtained at $279 \mathrm{~nm}$ (DMT), $291 \mathrm{~nm}$ (tetrahydroharmine), $320 \mathrm{~nm}$ (harmine) and $375 \mathrm{~nm}$ (harmaline).

\section{6. in-vitro cytotoxicity assessment}

Cell lineage

For assessing the anti-proliferative activity, a human non-tumor lineage (HaCaT, immortal keratinocytes) was used, which was provided by the Faculty of Dentistry of the University of Campinas, São Paulo, Brazil. The cell line was grown in T75 flasks (Corning) in complete medium (RPMI-1640, supplemented with $5 \%$ fetal bovine serum and $1 \%$ penicillin /streptomycin) at $37{ }^{\circ} \mathrm{C}$ under humid atmosphere supplemented with $5 \% \mathrm{CO}_{2}$. These conditions were used both for the maintenance of the cells and for the experiments. The cells were used between passages 5 and 12 .

\section{Assessment of cytotoxicity}

Briefly, the HaCaT cells were seeded in 96-well plates (T1 plates, between 3 to $6 \times 104$ cells $/ \mathrm{mL}, 100 \mu \mathrm{L} /$ well), incubated for $24 \mathrm{~h}$, treated with Ayahuasca sample $(0.15,1.5,15$ and $150 \mu \mathrm{g} / \mathrm{mL})$ and doxorubicin $(0.015,0.15,1.5 \mathrm{and} 15 \mu \mathrm{g} / \mathrm{mL}$, $100 \mu \mathrm{L} / \mathrm{mL}$ in triplicate), and then incubated for $48 \mathrm{~h}$ at $37^{\circ} \mathrm{C}$ in $5 \% \mathrm{CO}_{2}$. A second plate, denominated $\mathrm{T} 0$, was prepared to infer the absorbance value of untreated cells at the moment of sample addition. Untreated (T0 plate) and treated (T1 plates) cells were fixed with $50 \%$ trichloroacetic acid and stained with sulforhodamine dye ( $0.4 \%$ in acetic acid $1 \%)$. Absorbance was recorded at $540 \mathrm{~nm}$ using a microplate reader (Molecular Devices®, VersaMax model). Using the absorbance values, the cell growth (\%), at each sample concentration, was calculated considering at 100\% of cell growth the difference between the absorbances of treated cells after $48 \mathrm{~h}$ incubation (T1) and at the sample addition moment (T0). The curve cell growth vs. sample concentration was plotted and $\mathrm{GI}_{50}$ (concentration required for $50 \%$ growth inhibition) was calculated by sigmoidal regression using the Origin 8.0 software (Origin Lab Corporation, Northampton, MA, USA). These analyzes were performed at the Laboratory of Phytochemistry, Pharmacology and Experimental Toxicology (LAFTEX) at the Faculty of Pharmaceutical Sciences at UNICAMP.

\section{Results and discussion}

This work allowed to verify the influence of the environment and the drying process of Banisteriopsis caapi stems and Psychotria viridis leaves in the concentration of four psychotropic alkaloids present in Ayahuasca tea, prepared according to traditional ritual. Considering the great interest in the use of Ayahuasca for religious purposes and for treating various neurological and psychiatric conditions, studies of these variables provide important contributions to establish the necessary parameters to ensure reproducibility of the psychotropic and pharmacological effects $[4,15,33-37]$.

The standardizing all Ayahuasca tea preparations used in this study regarding the proportion of the plants, initial water volume, fire intensity, final yield and the samples storage at $-5^{\circ} \mathrm{C}$ before the freeze-drying process allowed to minimize the variability in the results of content of alkaloids caused by tea preparation, already reported by Mckenna [5] and in stability studies of samples monitored by Liquid Chromatography coupled to Mass Spectrometry (LC-ESI-MS/MS) showed that DMT and HRM alkaloids were stable over a period of 12 months when stored under refrigerated conditions, 
and the content of THH significantly dropped within a four-month interval, with different profiles among the evaluated samples [17].

During the study, the TF ecosystem exhibited an average annual rainfall of $2.585 \mathrm{~mm}$ and soil water retention capacity greater than the CAMP ecosystem who presented an average annual rainfall rate of $1.847 \mathrm{~mm}$, which is approximately $30 \%$ less than TF [38]. CAMP had still a longer summer period, which is common in the region and has already been confirmed in other studies [15,39], the soil is poor in minerals and there is high leaching caused by the water intensity of rainfall $[30,40]$. Considering the plant-environment relationship interferes with secondary metabolites produced by plants $[19,20,24,41,42]$, these factors together make the plants from CAMP ecosystem to suffer a period of water stress, which does not occur with the TF plants.

The evaluate of variation of the gross and relative levels of DMT, HRM, HRL and THH in Ayahuasca tea prepared with plants collected in Campinarana (CAMP) and Terra-firme (TF) evidence that parameters such as the place and time of collection, as well as the effect of the drying process of the plants for this study cause different results on the concentration of these four alkaloids in the Ayahuasca tea. Estrella-Parra et al. [4] showed that concentration variation has effect on the synergic activity among of these four alkaloids and may affects psychotropic effect of Ayahuasca tea.

Considering the content of alkaloids in Ayahuasca samples prepared with fresh plants collected in the winter (Table 1, samples A3 and A4), the concentration of DMT, HRL and THH were 54.22, 50.09 and 42.09\%, respectively; being higher in TF plants, whereas HRM concentration was similar for both ecosystems. However, when the plants were collected during the summer (Table 1, Samples A2 and A13), an increase in DMT concentration (44.34\%); decrease in the concentrations of HRL and HRM (46.83 and 48.04\%, respectively) with maintenance of THH concentration when comparing TF and CAMP was observed. Furthermore, when comparing two different years of harvesting in the same season (summer) (Table 1, samples A5 and A13 from CAMP and A2 and A7 from TF), samples A13 and A5 showed an increase of $49.6 \%$ in DMT content and 5.6\% for THH, with a decrease in HRL levels of $19.68 \%$ and for HRM of $20.58 \%$ compared with samples A2 and A7 of TF. Whereas a $24 \%$ decrease in DMT and $11.84 \%$ THH in samples A2 and A7 with a concomitant increase to $35.47 \%$ and $14.93 \%$ for HRL and HRM content was detected, showing how climatic interannual variations in water availability in the soil directly influence the content of alkaloids (Table 2). The significant decrease in soil water availability from January to November in the CAMP ecosystem was reflected in the samples with a decrease of $24 \%$ in DMT and $14.93 \%$ in HRM, whereas for TF samples, where the soil water availability variation was positive, an increase of $49.6 \%$ was observed for DMT and $5.6 \%$ for THH.

Previous analysis of several Ayahuasca samples obtained during five years from different religious groups revealed wide variation in the alkaloid profile [43]. Moreover, Ayahuasca plants showed marked alkaloid concentration variations when collected in different seasons at the same site [32]. These studies based their results on the different forms of preparation, the sources and the quantity/proportion of the plants used in Ayahuasca preparation. Variations found in this study are smaller than those found by Callaway [44] and Lanaro [32] (Table 3). Considering that herein standardized samples were used from the plant collection site to the preparation of Ayahuasca tea from a single religious source, the alkaloids variation levels found in this study are directly related to the season of collection and to the characteristics of the environment where the plants were obtained. These results show that to standardizing the proportions of plants used in the preparation of Ayahuasca, in an attempt to increase consumption safety and control the concentration of entheogenic compounds must necessarily consider the place and time of harvest [24].

The concentrations of HRM, HRL, and THH alkaloids detected showed that the conversion of HRM into HRL and from this to THH during decoction, as suggested by Callaway [44], in our samples occurred in a lower scale as detected for HRM and HRL content in the tea samples evaluated (Table 1). Less influence of decoction process on the variation in the content of alkaloids, reinforces the importance of standardizing the proportion/quantity of plants used in the preparation of Ayahuasca to avoid exacerbated variations in the tea alkaloid concentrations.

Regarding the ratios of Ayahuasca alkaloids prepared with fresh plants collected in the winter DMT/HRL, DMT/HRM, and DMT/THH were higher in plants from TF ecosystem, being $1.39,0.35$, and 0.21 respectively. Likewise, in the summer period, the highest ratios were found for the samples prepared with plants from the TF ecosystem, being 2.66 for DMT/HRL, 0.46 for DMT/HRM, and 0.28 for DMT/THH, when compared with the samples prepared with plants from the CAMP (Table 4). 
Table 1 Concentration of alkaloids (mg/L) and cytotoxic effect ( $\mathrm{GI}_{50} \mu \mathrm{g} / \mathrm{ml}$ ) observed for Ayahuasca prepared with fresh plants and after drying.

\begin{tabular}{|c|c|c|c|c|c|c|c|c|c|c|}
\hline \multicolumn{4}{|c|}{ Collect } & \multicolumn{2}{|c|}{ Drying } & \multicolumn{5}{|c|}{ Alkaloids (mg/L) } \\
\hline Month/Year & Site & Season & Sample & No & Yes & DMT & HRL & HRM & THH & $\mathbf{G I}_{50}$ \\
\hline \multirow[t]{4}{*}{ Aug/16 } & \multirow[t]{2}{*}{$\mathrm{TF}$} & \multirow[t]{2}{*}{$\mathrm{S}$} & $\mathrm{A} 2$ & $\mathrm{x}$ & & 73.74 & 27.72 & 161.34 & 263.94 & $80.5 \pm 5.1$ \\
\hline & & & A14 & & $60 / 60$ & 37.3 & 15.7 & 181.9 & 79.4 & n.t. \\
\hline & \multirow[t]{2}{*}{ Camp } & \multirow[t]{2}{*}{ W } & A3 & $\mathrm{x}$ & & 40.74 & 31.8 & 250.8 & 242.94 & $>150$ \\
\hline & & & A12 & & $60 / 60$ & 31.62 & 14.52 & 110.76 & 100.62 & $>150$ \\
\hline \multirow[t]{4}{*}{ Jan/16 } & \multirow[t]{2}{*}{$\mathrm{TF}$} & \multirow[t]{2}{*}{$\mathrm{W}$} & A4 & $\mathrm{x}$ & & 88.86 & 63.72 & 256.5 & 419.58 & $141.6 \pm 13.9$ \\
\hline & & & A10 & & $50 / 50$ & 39.72 & 30.66 & 198.0 & 230.88 & 150 \\
\hline & \multirow[t]{2}{*}{ Camp } & \multirow[t]{2}{*}{$\mathrm{S}$} & $\mathrm{A} 13$ & $\mathrm{x}$ & & 41.04 & 52.14 & 310.56 & 274.2 & n.t. \\
\hline & & & A6 & & $50 / 50$ & 40.44 & 23.34 & 129.48 & 134.52 & 150 \\
\hline \multirow[t]{9}{*}{ Nov/17 } & \multirow[t]{5}{*}{$\mathrm{TF}$} & \multirow[t]{5}{*}{$S$} & A7 & $\mathrm{x}$ & & 55.98 & 42.96 & 189.66 & 232.68 & $34.5 \pm 7.3$ \\
\hline & & & A8 & & $40 / 40$ & 65.1 & 51.54 & 240.12 & 256.32 & n.t. \\
\hline & & & A18 & & $50 / 50$ & 33.36 & 4.5 & 116.28 & 29.76 & n.t. \\
\hline & & & A11 & & $40 / 45$ & 52.0 & 33.4 & 238.8 & 206.6 & n.t. \\
\hline & & & A16 & & Sun & 37.08 & 5.46 & 140.58 & 40.5 & $119.5 \pm 0.5$ \\
\hline & \multirow[t]{4}{*}{ Camp } & \multirow[t]{4}{*}{$\mathrm{S}$} & A5 & $\mathrm{x}$ & & 81.42 & 41.88 & 246.3 & 290.58 & $>150$ \\
\hline & & & A9 & & $40 / 40$ & 62.94 & 11.28 & 173.76 & 97.08 & $>150$ \\
\hline & & & A17 & & $50 / 50$ & 55.5 & 19.2 & 149.28 & 96.54 & $>150$ \\
\hline & & & A15 & & Sun & 72.18 & 29.52 & 232.8 & 103.5 & $65.7 \pm 25.0$ \\
\hline \multirow[t]{2}{*}{ Feb/19 } & $\mathrm{TF}$ & $\mathrm{W}$ & A19 & & $43 / 45$ & 108.36 & 39.78 & 165.3 & 127.8 & $111.9 \pm 0.3$ \\
\hline & Camp & $\mathrm{S}$ & A20 & & $43 / 45$ & 98.94 & 29.76 & 119.1 & 111.42 & $25^{*}$ \\
\hline
\end{tabular}

$\mathrm{TF}$ = Terra Firme; Camp = Campinarana; Season: S = Summer, $\mathrm{W}$ = Winter; Samples: Ayahuasca prepared with fresh plants (A2-TF; A3-CAMP; A4-TF, A13-CAMP; A7-TF and A-5 CAMP); Drying : 60/60, $50 / 50,40 / 40,40 / 45,43 / 45=$ temperature $\left({ }^{\circ} \mathrm{C}\right)$ of drying $P$. viridis leaves and $B$. caapi stems, respectively; Sun = leaves and stems dried in the sun; $\mathrm{GI} 50(\mu \mathrm{g} / \mathrm{ml})=$ concentration of lyophilized tea necessary to inhibit the proliferation of HaCaT lineage cells by $50 \%$; ${ }^{*}$ approximate value depending on experimental values; nt= not test. Alkaloids concentration determined by HPLC-DAD. 
Table 2 Climatic variations occurred between the summer of 2016 and 2017 in the CAM P and TF ecosystems

\begin{tabular}{|c|l|c|c|c|c|}
\hline Ecosystem & Date & T ( $\mathbf{0}$ ) & Rainfall (mm) & Air humidity (\%) & Water in the soil (\%) \\
\hline TF & Aug/16 & 28.07 & 4.72 & 72.92 & 62.94 \\
\hline TF & Nov/17 & 28.50 & 3.92 & 73.27 & 82.84 \\
\hline CAMP & Jan/16 & 28.41 & 0.99 & 63.08 & 52.40 \\
\hline CAMP & Nov/17 & 30.56 & 0.17 & 57.10 & 6.57 \\
\hline \multicolumn{7}{|c|}{ TF: Terra firme; CAMP: Campinarana; T: temperature. Given values are monthly averages. }
\end{tabular}

Table 3 Comparison of alkaloid concentration in Ayahuasca samples prepared with and without standardization from different sources. Quantified by HPLC-DAD.

\begin{tabular}{|l|c|c|c|c|c|c|c|}
\hline \multicolumn{1}{|c|}{ Author } & Standard & $\begin{array}{c}\text { Source } \\
\text { (n) }\end{array}$ & $\begin{array}{c}\text { Samples } \\
\text { (n) }\end{array}$ & $\begin{array}{c}\text { DMT } \\
\text { (mg/L) }\end{array}$ & $\begin{array}{c}\text { HRL } \\
\text { (mg/L) }\end{array}$ & $\begin{array}{c}\text { HRM } \\
\text { (mg/L) }\end{array}$ & $\begin{array}{c}\text { THH } \\
\text { (mg/L) }\end{array}$ \\
\hline Callaway (2005) [44] & No & 4 & 20 & $160-5840$ & $100-900$ & $450-6250$ & $450-5260$ \\
\hline Lanaro et. al (2018) & No & 1 & 9 & $402-2070$ & $28-181$ & $295-2894$ & $850-2053$ \\
\hline This study & Yes & 1 & 20 & $41-108$ & $28-64$ & $161-311$ & $239-420$ \\
\hline
\end{tabular}

The ratio of THH/HRM both in the summer and winter seasons was higher and constant for samples of tea prepared with plants from TF ecosystem (Table 4), which is twice the ratio found by Callaway [44], with samples from UDV. However, considering the entheogenic effects of Ayahuasca for religious, health purposes, and the treatment for chemical dependency, to our knowledge, the best ratio of these two alkaloids is still unknown.

This is the first study describing parameters to standardize procedures and proportions of plants (P. viridis/B. caapi) to be used in the preparation of Ayahuasca, which is key for comparison of samples from different regions, and thus to assess the environmental effects on alkaloid concentration. Quantification of alkaloids in Ayahuasca samples used in religious rituals, will allow a more accurate assessment of the real psychotropic effect of this beverage. Furthermore, considering that active plant compounds also have relationship with the specie's genetic variability $[21,45]$, further studies are necessary to understand the role of genetic variability in alkaloid variations in plant tissue

To the present date, the preparations of Ayahuasca have been mainly done using fresh plant material. With the increasing popularity of the entheogenic effect and pharmacological benefits that Ayahuasca provides, applying postharvesting treatments, as dehydration, may contribute to increase the quality of Ayahuasca used in countries where $P$. viridis and B. caapi cultivation is limited $[5,12,17,46]$

In this context, this work analyzed the effect of the post-harvest drying process on the content of alkaloids in Ayahuasca tea prepared with B. caapi and P.viridis, dehydrated under the same temperatures $\left(40,50,60^{\circ} \mathrm{C}\right.$, and at sun). Ayahuasca tea made with plants dried at $60^{\circ} \mathrm{C}$, from both TF and CAMP ecosystems, (A14 samples and A12, Table 1) compared to the correspondent beverage prepared with fresh plants demonstrated a decrease of 49, 43, 12, and 69.9\% of DMT, HRL, HRM, THH content respectively to TF ecosystem, whereas to samples made with plants of CAMP ecosystem the decrease was of 22.4, 54.7, 56.0, and 59.3\% for DMT, HRL, HRM and THH content, respectively. When samples from both TF and

CAMP prepared with dehydrated plants at $50^{\circ} \mathrm{C}$ (samples A10 and A6, Table 1) are compared with their corresponding samples prepared with fresh plants (samples A4 and A13, Table 1) and with TF plant sample demonstrated 55.4, 51.8, 22.8 and 45.3 (mg/L) for DMT, HRL, HRM, and THH concentrations, respectively. Regarding samples with CAMP plants, the reduction of alkaloid concentration was $1.5,55.2,58.3$, and 50.9 (mg/L) for DMT, HRL, HRM, and THH, sequentially. These results may have relationship with thermal instability of labile compounds in Ayahuasca tea, which can cause reactions during the drying process [22, 47]. 
Table 4 Alkaloids ratios observed for Ayahuasca prepared with fresh plants and after drying.

\begin{tabular}{|c|c|c|c|c|c|c|c|c|c|c|c|}
\hline \multicolumn{4}{|c|}{ Coleta } & \multicolumn{2}{|c|}{ Drying } & \multicolumn{6}{|c|}{ Alkaloids ratio } \\
\hline Month/Year & Site & Season & Sample & No & Yes & DMT/HRL & DMT/HRM & DMT/THH & THH/HRL & THH/HRM & HRM/HRL \\
\hline \multirow[t]{4}{*}{ Aug/16 } & \multirow[t]{2}{*}{$\mathrm{TF}$} & \multirow[t]{2}{*}{$S$} & $\mathrm{~A} 2$ & $\mathrm{x}$ & & 2.66 & 0.46 & 0.28 & 9.52 & 1.64 & 5.82 \\
\hline & & & $\mathrm{A} 14$ & & $60 / 60$ & 2.38 & 0.21 & 0.47 & 5.06 & 0.44 & 11.59 \\
\hline & \multirow[t]{2}{*}{ Camp } & \multirow[t]{2}{*}{$\mathrm{W}$} & A3 & $\mathrm{x}$ & & 1.28 & 0.16 & 0.17 & 7.64 & 0.97 & 7.89 \\
\hline & & & $\mathrm{A} 12$ & & $60 / 60$ & 2.18 & 0.29 & 0.31 & 6.93 & 0.91 & 7.63 \\
\hline \multirow[t]{4}{*}{ Jan/16 } & \multirow[t]{2}{*}{$\mathrm{TF}$} & \multirow[t]{2}{*}{ W } & $\mathrm{A} 4$ & $\mathrm{x}$ & & 1.39 & 0.35 & 0.21 & 6.58 & 1.64 & 4.03 \\
\hline & & & A10 & & $50 / 50$ & 1.3 & 0.2 & 0.17 & 7.53 & 1.17 & 6.46 \\
\hline & \multirow[t]{2}{*}{ Camp } & \multirow[t]{2}{*}{ S } & A13 & $\mathrm{x}$ & & 0.79 & 0.13 & 0.15 & 5.26 & 0.88 & 5.96 \\
\hline & & & A6 & & $50 / 50$ & 1.73 & 0.31 & 0.3 & 5.76 & 1.04 & 5.55 \\
\hline \multirow[t]{9}{*}{ Nov/17 } & \multirow[t]{5}{*}{$\mathrm{TF}$} & \multirow[t]{5}{*}{$S$} & A7 & $\mathrm{x}$ & & 1.3 & 0.3 & 0.24 & 5.42 & 1.23 & 4.41 \\
\hline & & & A8 & & $40 / 40$ & 1.26 & 0.27 & 0.25 & 4.97 & 1.07 & 4.66 \\
\hline & & & A18 & & $50 / 50$ & 7.41 & 0.29 & 1.12 & 6.61 & 0.26 & 25.84 \\
\hline & & & A11 & & $40 / 45$ & 1.56 & 0.22 & 0.25 & 6.19 & 0.87 & 7.15 \\
\hline & & & A16 & & sol & 6.79 & 0.26 & 0.92 & 7.42 & 0.29 & 25.75 \\
\hline & \multirow[t]{4}{*}{ Camp } & \multirow[t]{4}{*}{$S$} & A5 & $\mathrm{x}$ & & 1.94 & 0.33 & 0.28 & 6.94 & 1.18 & 5.88 \\
\hline & & & A9 & & $40 / 40$ & 5.58 & 0.36 & 0.65 & 8.61 & 0.56 & 15.40 \\
\hline & & & A17 & & $50 / 50$ & 2.89 & 0.37 & 0.57 & 5.03 & 0.65 & 7.78 \\
\hline & & & A15 & & sol & 2.45 & 0.31 & 0.7 & 3.51 & 0.44 & 7.89 \\
\hline \multirow[t]{2}{*}{ Feb/19 } & $\mathrm{TF}$ & W & A19 & & $43 / 45$ & 2.72 & 0.66 & 0.85 & 3.21 & 0.77 & 4.16 \\
\hline & Camp & $\mathrm{S}$ & A20 & & $43 / 45$ & 3.32 & 0.83 & 0.89 & 3.74 & 0.94 & 4.00 \\
\hline
\end{tabular}

TF=Firme; Camp = Campinarana; Season: S = Summer, W = Winter; Samples: Ayahuasca prepared with fresh plants (A2-TF; A3-CAMP; A4-TF, A13-CAMP; A7-TF and A-5 CAMP); Drying : 60/60, 50/50, 40/40, $40 / 45,43 / 45=$ temperature $\left({ }^{\circ} \mathrm{C}\right)$ of drying $P$. viridis leaves and $B$. caapi stems, respectively; Sun = leaves and stems dried in the sun; Ratios: concentration $N$, $N$ - dimethyltryptamine (DMT) as a function of Harmaline (HML) concentration, Harmine (HRM), tetrahydroharmine (THH); THH concentration as a function of HRL, HRM and HRM concentration as a function of HRL determined by HPLC-DAD. 
Drying temperatures at 50 and $60^{\circ} \mathrm{C}$ resulted in a high depletion of active compounds in Ayahuasca. Also, a high variation of compound depletion patterns, especially for DMT, HRL, and THH was observed. This observation emphasizes the sensitivity of these compounds to these temperatures, and therefore are unsuitable for drying Ayahuasca plants, since thermal sensitivity and susceptibility to degradation affect the stability of the compound [23]. Independently of the environment of collect, all the leave samples of $P$. viridis darkened and stems of $B$. caapi became brittle after drying at 50 to $60^{\circ} \mathrm{C}$ [22], and which is also related to high temperature, since high temperature leads to irreversible and adverse chemical reactions that cause degradation of product quality [47].

Comparing Ayahuasca samples made with plants dried at $40^{\circ} \mathrm{C}$ (samples A8 and A9, Table1) with their corresponding samples (samples A7 and A5, Table 1), an increase in alkaloid concentrations in Ayahuasca samples with TF plants, being 16.29, 19.97, 26.62, and 10.16\% for DMT, HRL, HRM, and THH were detected. Whereas in samples with CAMP plants a reduction of 22.70, 73.07, 29.45, and 66.59\% for DMT, HRL, HRM, and THH was observed.

While drying at $40^{\circ} \mathrm{C}$ showed unexpected results with reduction and increase of alkaloids content when compared with their corresponding samples, which may have been influenced by the morphological characteristics of the plants, that according to Chua et al. [23] having also influenced the final quality by drying. Samples dried by direct solar heat also showed instability for DMT and $\beta$-carbolinic compounds concentration. Furthermore, drying in the sun increases the risk of contamination by exposure of the material by unknown factors, therefore beverages prepared with these inputs could lead to adverse effects [48].

In light of the distinct characteristics of each species that take part in Ayahuasca tea, the plant parts used in the tea preparation, and considering the concentrations found in Ayahuasca prepared with plants dried at 40 and $50^{\circ} \mathrm{C}$, samples of Ayahuasca prepared with dried plants under different temperatures for each species were assessed, establishing conditions of (a) $45^{\circ} \mathrm{C}$ for stems and $40^{\circ} \mathrm{C}$ for leaves and (b) $45^{\circ} \mathrm{C}$ for stems and t $43^{\circ} \mathrm{C}$ for leaves (Figure 2).

Considering the samples with stems and leaves dehydrated at $40 / 45$ and $43 / 45^{\circ} \mathrm{C}$ respectively (Samples $\mathrm{A} 11$, A19 and A20, Table 1) the alkaloid concentration of HRL was low but relatively constant. THH/HRM ratios of both samples with CAMP and TF plants in winter and summer were close to 1:1, being constant in most samples (Table 4). For DMT concentration of Ayahuasca samples prepared with leaves dried at 40 to $43^{\circ} \mathrm{C}$ (sample A11, A19, A120, Table 1), sample A11 with leaves dried at $40^{\circ} \mathrm{C}$ had a low variation in the DMT content. However, there was also a low DMT content (52.0 $\mathrm{mg} / \mathrm{L}$ ) when compared to samples A19 and A20, prepared with leaves dehydrated at $43^{\circ} \mathrm{C}$, that exhibited the greatest DMT concentration (108 and 98,94 mg/L) in both TF and CAMP ecosystems, respectively. This result indicates that DMT could be sensitive to temperatures above $43^{\circ} \mathrm{C}$, as occur with trigonelline alkaloid during the coffee roasting process [49].

Ratios of THH/HRM 1:1 and 1:5 were found in report by Callaway [44] and Callaway et al. [43], respectively. These studies indicated that there could be a route to reduce HRM to HRL and from this to THH, however they did not investigate the interference of plant drying or the stability of the ratio between alkaloids.

Drying plants could be an answer to meet the growing demand for Ayahuasca products. Considering the synergistic action of the tea molecules, both the quantitative maintenance of DMT and the ratio between the $\beta$-carbolinic compounds appear to be fundamental for the psychotropic effects of Ayahuasca. The highest DMT concentration and greater stability between THH/HRM ration found in Ayahuasca made with plants dried at 43 and $45^{\circ} \mathrm{C}$, for $P$. viridis leaves and B.caapi stems, respectively allow to indicate that these temperatures in forced circulation oven are suitable for drying these plants, allowing to indicate the use of these drying parameters in the traditional preparation of Ayahuasca. 


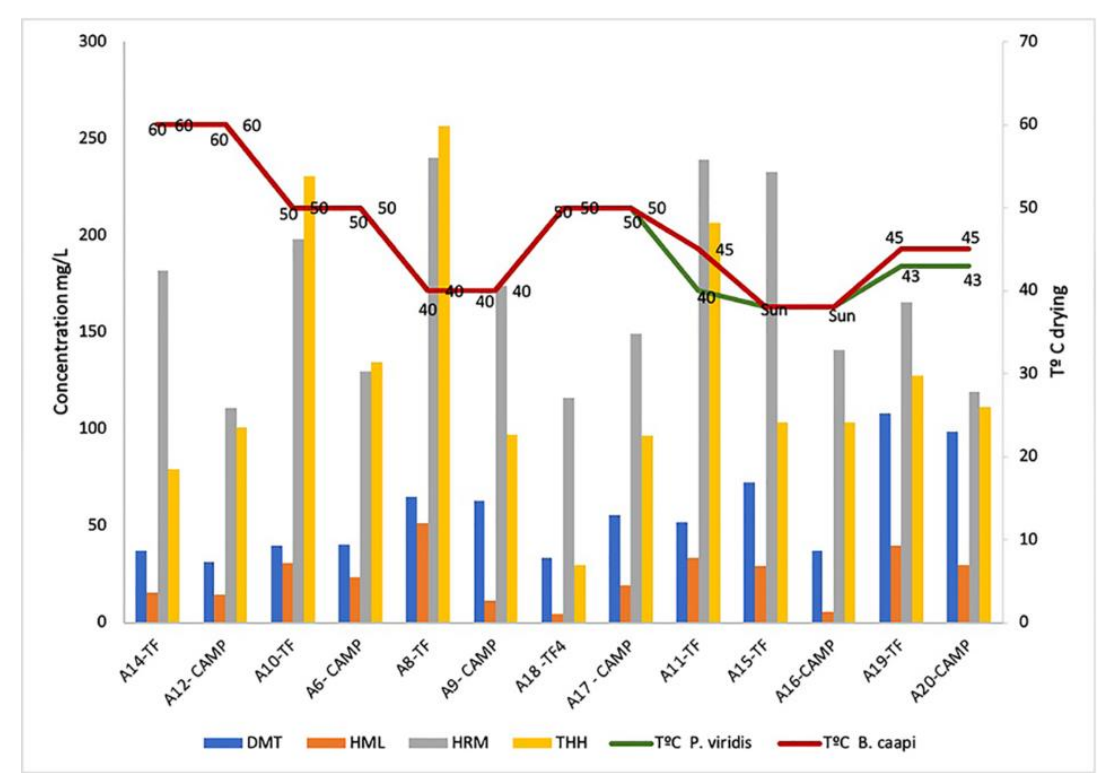

Figure 2 Influence of drying temperature on the concentration (mg/L) of DMT, HRL, HRM and THH in Ayahuasca samples prepared with dehydrated B. caapi stems and P.viridis leaves.

Finally, the influence of variation in the chemical composition of Ayahuasca tea tested in vitro for antiproliferative activity was evaluated (Table 1, Figure 3). In vitro evaluation benefits from culturing cells in a conducive and controlled environment, besides ease and speed of assay execution and relatively low cost [50]. However, the test is a target-oriented assessment. In the model defined by this study (immortal human keratinocytes, HaCaT), in vitro evaluation will help to highlight possible effects of Ayahuasca tea on the proliferation of normal tissues such as skin, mucous membranes and bone marrow [51].

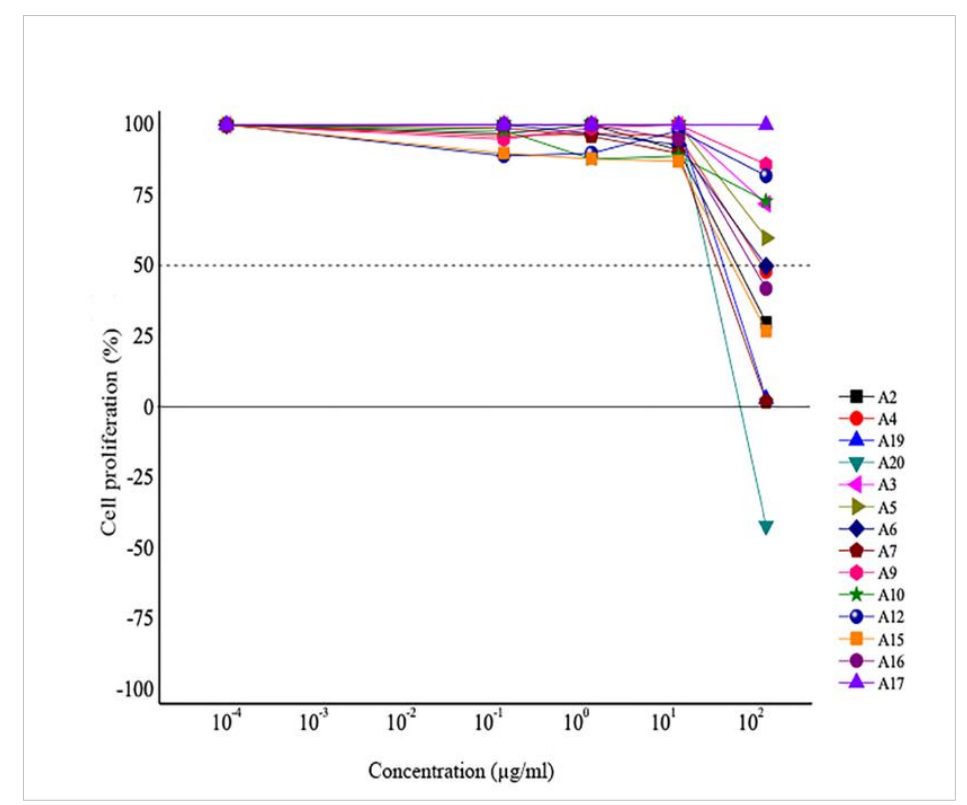

Figure 3 Proliferation of immortal human keratinocytes (HaCaT) after $48 \mathrm{~h}$ of exposure to different samples of Ayahuasca tea (see Table 1 for collection and drying conditions for each sample).

The evaluation of anti-proliferative activity after $48 \mathrm{~h}$ of exposure (Figure 3 ) followed the protocol developed by the National Institute of Cancer-USA [52]. In this model, cytostatic activity can be expressed as the sample concentration necessary to inhibit cell proliferation by $50 \%$ ( $\mathrm{GI}_{50}$ ) [53]. Furthermore, $\mathrm{GI}_{50}$ values greater than $30 \mu \mathrm{g} / \mathrm{ml}$ are representative of samples that do not significantly affect cell proliferation [54]. Analyzing the results shown in Table 1 based on these criteria, $90 \%$ of all the samples analyzed exhibited GI50 above $150 \mu \mathrm{g} / \mathrm{ml}$, which means no cytotoxicity on the proliferation of normal human cells (HaCaT) (Figure. 3). To Ayahuasca tea prepared with dried plants, only 
sample A20, prepared with dried leaves at $43^{\circ} \mathrm{C}$ and stems at $45^{\circ} \mathrm{C}$ collected in CAMP during the summer showed light cytotoxic activity when tested on immortal human keratinocytes (GI $50 \approx 30 \mu \mathrm{g} / \mathrm{ml}, \mathrm{HaCaT}$ ) (Figure. 3).

Comparing these results of anti-proliferative activity with the levels of DMT, HRL, HRM, and THH, as well as with the relative proportions between them (Table 1), there is no evident correlation between the variations observed for these compounds and the cytostatic effect observed in $\mathrm{GI}_{50} \approx 30 \mu \mathrm{g} / \mathrm{ml}$ for samples A20. Therefore, a more in-depth assessment of the chemical profile of these sample compared to those that did not have a cytotoxic effect are necessary to identify the possible components involved in this light anti-proliferative effect. A systematic review of studies with humans has shown that acute, subacute and long-term use of Ayahuasca have low toxicity [55]. Moreover, assessments of biochemical parameters related to liver damage in serum in 22 volunteers who consumed Ayahuasca twice a month or more for at least one year indicate that chronic consumption of Ayahuasca in a religious context apparently does not affect liver function [56]. Furthermore, both DMT and HRM demonstrated a cyto-protective effect in vitro on different cell lines of human neurons submitted to hypoxia [57] or by exposure to 6-hydroxydopamine [58].

\section{Conclusion}

Variation of alkaloids concentration in Ayahuasca tea has relationship with the place and time of harvest of the species. Rainfall and water capacity of the soil showed to have straight relationship with the alkaloid contents of DMT, HRL, HRM, and THH in Ayahuasca. In the winter period, with higher rainfall, the alkaloids concentration in Ayahuasca prepared with plants from the TF ecosystem increases. Nevertheless, plants from CAMP seemed more adapted to water stress and the tea made with plants from this ecosystem had lower seasonal variation on the alkaloid's concentration.

Data reported herein demonstrated that drying temperature influences the quality of the components detected in the plants used to prepare Ayahuasca. Therefore, the drying parameters of $B$. caapi and $P$ viridis species should be standardized based on the morphological characteristics of each species. In this study, the most suitable conditions were achieved in a forced air circulation oven with temperatures of $43^{\circ} \mathrm{C}$ for leaves and $45^{\circ} \mathrm{C}$ for stems. This allowed a constant and greater DMT concentrations, as well as maintained constant the quantitative proportion among the $ß$ - carbolines in Ayahuasca prepared with plants from either Campinarana or Terra-Firme ecosystems.

Regarding the in vitro cytotoxicity, the results indicated that variations of alkaloids concentrations in Ayahuasca prepared with dehydrated or fresh plants did not show cytotoxic effects on human keratinocytes with relationship to DMT, HRL, HRM, and THH. Except for sample A20. Therefore, a more in-depth assessment of the chemical profile this sample compared to those that did not show a cytotoxic effect may identify the possible components involved in this slightly anti-proliferative effect. We consider that the cytotoxicity evaluation results found here, considering the antiproliferative activity as a parameter, can potentially assist in refining screening samples for testing in vivo.

\section{Compliance with ethical standards}

\section{Acknowledgments}

OFM is thankful the Ministry of Science, Technology and Innovation of Brazil for the four years of financial support during the doctoral study at the University of São Paulo-USP, Brazil. All authors are grateful to the Centro Espírita Beneficente União do Vegetal (CBUDV) for the plants and Ayahuasca sample analyzed in this study and also for the financial support.

\section{Author contributions}

The work is part of the doctoral thesis of OFM who conceived the designed and all stages of research, in addition to the preparation and revision of the manuscript. MA, MAF and ALTGR contributed with concepts, design, analyses to the study and also with review. IMOS and RSM contributed with analyses, preparation and revision of the manuscript, JLC contributed with analyses to the study. All authors discussed, edited and approved the final version.

\section{Disclosure of conflict of interest}

None conflicts of interest to declare. The manuscript has not been previously submitted or published in other journal and is not being considered for publication elsewhere. 


\section{References}

[1] Callaway JC, McKenna DJ, Grob CS, et al. Pharmacokinetics of Hoasca alkaloids in healthy humans. Journal of Ethnopharmacology 1999; 65:243-256.

[2] Schenberg EE. Ayahuasca and cancer treatment. SAGE Open Medicine 2013; 1:205031211350838.

[3] Wang YH, Samoylenko V, Tekwani BL, et al. Composition, standardization and chemical profiling of Banisteriopsis caapi, a plant for the treatment of neurodegenerative disorders relevant to Parkinson's disease. Journal of Ethnopharmacology 2010; 128:662-671.

[4] Estrella-Parra EA, Almanza-Pérez JC, Francisco, et al. Ayahuasca: Uses, Phytochemical and Biological Activities. Natural Products and Bioprospecting 2019; 9:251-265.

[5] McKenna DJ. Clinical investigations of the therapeutic potential of ayahuasca: Rationale and regulatory challenges. Pharmacology and Therapeutics 2004; 102:111-129.

[6] Miller MJ, Albarracin-Jordan J, Moore C, et al. Chemical evidence for the use of multiple psychotropic plants in a 1,000-year-old ritual bundle from South America. Proceedings of the National Academy of Sciences 2019; 116: 11207-11212.

[7] Gaujac A, Navickiene S, Collins MI, et al. Analytical techniques for the determination of tryptamines and $\beta$ carbolines in plant matrices and in psychoactive beverages consumed during religious ceremonies and neoshamanic urban practices. Drug Testing and Analysis 2012; 4:636-648.

[8] Labate BC, Feeney K. Ayahuasca and the process of regulation in Brazil and internationally - Implications and challenges. International Journal of Drug Policy 2012; 23:154-161.

[9] Tupper KW. The globalization of ayahuasca: Harm reduction or benefit maximization? International Journal of Drug Policy 2008; 19:297-303.

[10] Grob CS, Mckenna DJ, Callaway JC, et al. farmacologia da Hoasca, planta alucinógena usada em Contexto ritual no Brasil. The Journal of Nervous and Mental Disease 1996; 184:86-94.

[11] Pires APS, Dizioli C, Oliveira R De, et al. Gas Chromatographic Analysis of Dimethyltryptamine and b -Carboline Alkaloids in Ayahuasca an Amazonian Psychoative Plant Beverage. Phytochemical Analysis 2009; 20:149-153.

[12] Santos RG, Bouso JC, Hallak JEC. Ayahuasca, dimethyltryptamine, and psychosis: a systematic review of human studies. Therapeutic Advances in Psychopharmacology 2017; 7:141-157.

[13] Souza RCZ, Zandonadi FS, Freitas DP, et al. Validation of an analytical method for the determination of the main ayahuasca active compounds and application to real ayahuasca samples from Brazil. Journal of Chromatography B: Analytical Technologies in the Biomedical and Life Sciences 2019; 1124:197-203.

[14] Cavalcante AD, Cardoso GA, Oliveira FLP De, et al. Influence of Environmental Factors and Cultural Methods on the Content of N,N-Dimethyltryptamine in Psychotria viridis (Rubiaceae). Journal of the Brazilian Chemical Society 2018; 00:1-11.

[15] Miranda OF, Souza SEXF, Milan RJ, et al. Influence of environment on the leaf morpho-anatomy and histochemical of the ayahuasca leaf: Populations cultivated in extra-Amazonian regions. Acta Scientiarum Biological Sciences 2020; 42:1-12.

[16] Kaasik H, Souza RCZ, Zandonadi FS, et al. Chemical Composition of Traditional and Analog Ayahuasca. Journal of Psychoactive Drugs 2020; 00:1-11.

[17] Silveira G de O, Santos RG dos, Rebello LF, et al. Stability evaluation of DMT and Harmala alkaloids in ayahuasca tea samples. Molecules 2020; 25:5-7.

[18] Santos BWL, Oliveira RC de, Sonsin-Oliveira J, et al. Biodiversity of $\beta$-Carboline Profile of Banisteriopsis caapi and Ayahuasca, a Plant and a Brew with Neuropharmacological Potential. Plants 2020; 9:870.

[19] Ncube B, Finnie JF, Van Staden J. Quality from the field: The impact of environmental factors as quality determinants in medicinal plants. South African Journal of Botany 2012; 82:11-20.

[20] Osbourn AE, Qi X, Townsend B, et al. Dissecting plant secondary metabolism - constitutive chemical defences in cereals. New Phytologist 2003; 159:101-108.

[21] Figueira GM, Ramelo PR, Ogasawara DC, et al. A set of microsatellite markers for Arrabidaea chica (Bignoniaceae), a medicinal liana from the Neotropics. American Journal of Botany 2010; 97:63-64. 
[22] Orphanides A, Goulas V, Gekas V. Drying Technologies: Vehicle to High-Quality Herbs. Food Engineering Reviews 2016; 8:164-180.

[23] Chua LYW, Chong CH, Chua BL, et al. Influence of Drying Methods on the Antibacterial, Antioxidant and Essential Oil Volatile Composition of Herbs: a Review. Food and Bioprocess Technology (2019) 2019; 12:450-476.

[24] Liebelt DJ, Jordan JT, Doherty CJ. Only a matter of time: the impact of daily and seasonal rhythms on phytochemicals. Phytochemistry Reviews 2019; 18:1409-1433.

[25] Ng ZX, Yong PH, Lim SY. Customized drying treatments increased the extraction of phytochemicals and antioxidant activity from economically viable medicinal plants. Industrial Crops and Products 2020; 155 : 112815.

[26] Zarur J. Um comentário sobre a classificação de Koppen. Revista brasileira de geografia 1943; 2:250-254.

[27] Alvares CA, Stape JL, Sentelhas PC, et al. Köppen's climate classification map for Brazil. Meteorologische Zeitschrift $2013 ; 22: 711-728$.

[28] Ab'Saber AN. Bases para o estudo dos ecossistemas da Amazônia brasileira. Estudos Avançados 2002; 16 : 7-30.

[29] Barbosa RI, Miranda I de S. Fitofisionomia e diversidade vegetal das savanas de Roraima. In: Barbosa RI, Xaud HAM, Costa SJM, eds. FEMACT Savanas de Roraima - Etnoecologia, Biodiversidade e Potencialidades Agrosilvipastoris. 1th ed. Manaus, AM, Brazil; 2004. p. 61-78.

[30] Silveira LHC, Rezende AV, Vale AT do. Teor de umidade e densidade básica da madeira de nove espécies comerciais amazônicas. Acta Amazonica 2013; 43:179-184.

[31] Giumanini GA, Chiavari G, Musiani MM, et al. N-Permethylation of primary and secondary aromatic-amines. Synthesis-Stuttgart 1980; 9:743-6.

[32] Lanaro R, Calemi DB de A, Togni LR, et al. Ritualistic Use of Ayahuasca versus Street Use of Similar Substances Seized by the Police: A Key Factor Involved in the Potential for Intoxications and Overdose? Journal of Psychoactive Drugs 2015; 47:132-139.

[33] Breeksema JJ, Niemeijer AR, Erwin Krediet. et al. Psychedelic Treatments for Psychiatric Disorders: A Systematic Review and Thematic Synthesis of Patient Experiences in Qualitative Studies. CNS Drugs 2020; 34: $925-926$.

[34] Santos RG dos, Hallak JEC. Ayahuasca, an ancient substance with traditional and contemporary use in neuropsychiatry and neuroscience. Epilepsy \& Behavior journal 2019; DOI: 10.1016/j.yebeh.2019.04.053.

[35] Hamill J, Hallak J, Dursun SM, et al. Ayahuasca: Psychological and Physiologic Effects, Pharmacology and Potential Uses in Addiction and Mental Illness. Current Neuropharmacology 2019; 17:108-128.

[36] Orsolini L, Chiappini S, Papanti D, et al. How does ayahuasca work from a psychiatric perspective? Pros and cons of the entheogenic therapy. Human Psychopharmacology Clinical \& Experimental 2020; 35: e2728.

[37] Romeo B, Karila L, Martelli C, et al. Efficacy of psychedelic treatments on depressive symptoms: A meta-analysis. Journal of Psychopharmacology 2020; 24: 1079-1085.

[38] Agritempo. Pesquisa de dados meteorológicos para Presidente Figueiredo, AM. [Internet]. Agritempo- Sistema de Monitoramento agrometeorológico. [Cited 2018 Oct 14] available from https://www.agritempo.gov.br/agritempo.

[39] Moreira LJ da S. Química, física, minerologia e teores de metais pesados em solos do Estado do Amazonas. Universidade [PhD. Thesis]. Viçosa -MG, BR. University of Vicosa; 2016.

[40] Rodrigues TE, Oliveira Junior RC, Santos PL, et al. Caracterização e classificação dos solos do município de Presidente Figueiredo, Estado do Amazonas. Ministério da Agricultura Pecuária e Abastecimento, $2001 ; 50$.

[41] Liesenfeld V, Gentz P, De Freitas EM, et al. Leaf morphology and anatomy of Asteraceae of the Pampas biome (Sand-fields). Flora 2019; e151418.

[42] Liu W, Yin D, Li N, et al. Influence of environmental factors on the active substance production and antioxidant activity in Potentilla fruticosa L. and its quality assessment. Scientific Reports 2016; 6:1-18.

[43] Callaway JC, Brito GS, Neves ES. Phytochemical Analyses of Banisteriopsis Caapi and Psychotria Viridis. Journal of Psychoactive Drugs 2005; 37:37-41.

[44] Callaway JC. Various alkaloid profiles in decoctions of banisteriopsis caapi. Journal of Psychoactive Drugs 2005; 37:151-155. 
[45] Gupta AK, Mishra R, Singh AK, et al. Genetic variability and correlations of essential oil yield with agro-economic traits in Mentha species and identification of promising cultivars. Industrial Crops and Products 2017; 95:726732.

[46] Palhano-Fontes F, Barreto D, Onias H, et al. Rapid antidepressant effects of the psychedelic ayahuasca in treatment-resistant depression: a randomized placebo-controlled trial. 2018; 49:655-663.

[47] Cernîșev S. Effects of conventional and multistage drying processing on non-enzymatic browning in tomato. Journal of Food Engineering 2010; 96:114-118.

[48] Alibas I, Zia MP, Yilmaz A, et al. Drying kinetics and quality characteristics of green apple peel (Mallus communis L. var. "Granny Smith") used in herbal tea production. Journal of Food Processing and Preservation 2020; 44: e 14332.

[49] Marcucci CT, De Toledo Benassi M, Almeida MB, et al. Teores de trigonelina, ácido 5-cafeoilquínico, cafeína e melanoidinas em cafés solúveis comerciais brasileiros. Química Nova 2013; 36: 544-548.

[50] Mori H, Hara M. Cultured stem cells as tools for toxicological assays. Journal of Bioscience and Bioengineering 2013; 116:647-652.

[51] Muller PY, Milton MN. The determination and interpretation of the therapeutic index in drug development. Nature Reviews 2012; 11:751-761.

[52] Monks A, Scudiero P, Skehan P, et al. Feasability of a high-flux anticancer drug screen using a diverse panel of cultured human cell lines. Journal of the National Cancer Institute 1991; 83:757-766.

[53] Shoemaker RH. The NCI60 Human tumuor cell lines anticancer drug screen. Nature Reviews Cancer 2006; 6: 813823.

[54] Fouche G, Cragg GM, Pillay P, et al. In vitro anticancer screening of South African plants. Journal of Ethnopharmacology 2008; 119:455-461.

[55] Dos Santos RG, Balthazar FM, Bouso JC, et al. The current state of research on ayahuasca: A systematic review of human studies assessing psychiatric symptoms, neuropsychological functioning, and neuroimaging. Journal of Psychopharmacology 2016; 30:1230-1247.

[56] Mello SM, Soubhia PC, Silveira G, et al. Effect of Ritualistic Consumption of Ayahuasca on Hepatic Function in Chronic Users. Journal of Psychoactive Drugs 2019; 51:3-11.

[57] Szabo A, Kovacs A, Riba J, et al. The Endogenous Hallucinogen and Trace Amine N,N-Dimethyltryptamine (DMT) Displays Potent Protective Effects against Hypoxia via Sigma-1 Receptor Activation in Human Primary iPSCDerived Cortical Neurons and Microglia-Like Immune Cells. Frontiers in Neuroscience 2016; 10:423.

[58] Katchborian-Neto A, Santos WT, Nicácio KJ, et al. Neuroprotective potential of Ayahuasca and untargeted metabolomics analyses: applicability to Parkinsons disease. Journal of Ethnopharmacology 2020; 255 : e112743.

\section{Author's short biography}

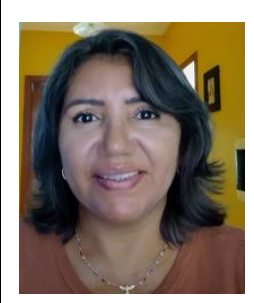

Dr. Ordilena F. Miranda develops research at the Biodiversity Coordination (CoBio) of the National Institute for Research in the Amazon (INPA) in Manaus, Amazonas, Brazil. She participates as a permanent member of the Research Group on Ecology and Evolution of Amazonian Plants (GP-EEPA-CNPq). Ecophysiology and biochemistry of Amazon plants is his main line of research, with a primary focus on Psychotria viridis and Banisteriopsis caapi (plants that have traditionally been used for the preparation of Ayahuasca). 